\title{
Changing Strategy for Aortic Stenosis by Transcatheter Valve Treatment in Japan
}

\author{
Junjiro Kobayashi, MD
}

$\mathbf{T}$ he standard operation for symptomatic severe aortic stenosis (AS) is surgical aortic valve replacement (SAVR). However, the mortality rate of SAVR increases with age, depressed left ventricular function, or multiple comorbidities. Transcatheter aortic valve replacement (TAVR) has emerged as an alternative treatment for these high-risk patients. More than 35,000 patients with severe AS have been treated by TAVR since the first clinical application in 2002 by Cribier et al. ${ }^{1}$ Recently, the ESC/EACTS valve guideline $2012^{2}$ outlined the recommendation of TAVR for patients who are not optimal for SAVR, based on the Partner trials $^{3,4}$ (Table 1).

\section{Article p 359}

At present, 2 types of TAVR devices are widely used in Europe and the United States. One is the balloon-expandable Edwards-SAPIEN prosthesis (Edwards Lifesciences, Irvine, CA, USA), and the other is the self-expandable CoreValve revalving prosthesis (Medtronic Inc, Minneapolis, MN, USA). ${ }^{5}$ These 2 devices have been under clinical trial in Japan since 2010 and 2011, respectively. In this issue of the Journal, Maeda et al report their initial experience of implanting SAPIEN valves in 15 patients who were from a clinical trial among 51 cases who underwent TAVR in Osaka University Hospital, Japan. ${ }^{6}$ They demonstrate similar initial clinical results to previous observational studies and randomized clinical trials of TAVR in other Western countries., ${ }^{3,4-12}$ There was no operative mortality or stroke, but patients had an average STS score of 10. Although the follow-up period was limited, there was only one non-cardiac death up to 848 days (average, 6 months). A permanent pacemaker was implanted in 2 cases. However, the reason for implantation was not complete heart block. Ef- fective orifice area was $1.7 \mathrm{~cm}^{2}$ on average, which is larger than that expected for a tissue valve that would be implanted when SAVR is performed. Mild prosthetic regurgitation occurred in $80 \%$ of patients, and none to trivial in $20 \%$. Interestingly, 3 patients underwent TAVR under the support of cardiopulmonary bypass because of poor left ventricular function. The indication of TAVR with cardiopulmonary bypass should be considered in the future.

The major concerns regarding TAVR are listed in Table 2. In the real world, the technical success rate of TAVR is 98$99 \%$, and the 30-day mortality rate is $12 \% .^{7-9}$ In the PARTNER B trial, there was a dramatic $20 \%$ survival benefit and $18.3 \%$ reduction in the combined risk of death or major stroke at 1 year after TAVR using the SAPIEN valve. ${ }^{3}$ Although anecdotal late valve dysfunction has been reported, the longest surviving patient at 6.5 years in the original Criber series still has normal valve function. Prosthesis-patient mismatch (PPM) is a concern after SAVR for severe AS, but currently PPM is thought to be absent after TAVR when a correctly sized transcatheter heart valve is selected in relation to the annular size, except with the valve-in-valve technique. ${ }^{13}$

Neurologic complication is an ominous problem after SAVR. Stroke is thought to be caused by embolism during manipulation of the diseased aorta or jet flow to the atheroma, and neurocognitive dysfunction is caused by cerebral microembolism during cardiopulmonary bypass. The PARTNER trial A demonstrated a 2.2-fold higher incidence of stroke in TAVR patients compared with SAVR in high-risk patients. ${ }^{4}$ Nontransfemoral TAVR consistently showed a 2.3 -fold higher incidence of post-procedural neurologic events. The higher risk of stroke with the transapical procedures may be associated with patient- and disease related factors, rather than intrinsic feature of the procedure per se. The transapical approach

Table 1. Recommendations for the Use of Transcatheter Aortic Valve Replacement in the ESC/EACTS Guideline

\section{Recommendation}

TAVR is indicated in patients with severe symptomatic AS who are not suitable for AVR as assessed by a heart team and who are likely to gain improvement in their quality of life and to have a life expectancy of more than 1 year after consideration of their comorbidity.

TAVR should be considered in high-risk patients with severe symptomatic AS who may still be suitable for surgery, but in whom TAVR is favored by a heart team based on the individual risk profile and anatomic suitability.

AS, aortic stenosis; AVR, aortic valve replacement; TAVR, transcatheter aortic valve replacement. (Revised from the 2012 guidelines on the management of valvular heart disease. ${ }^{2}$ )

The opinions expressed in this article are not necessarily those of the editors or of the Japanese Circulation Society.

Received December 11, 2012; accepted December 12, 2012; released online January 10, 2013

Department of Cardiovascular Surgery, National Cerebral and Cardiovascular Center, Suita, Japan

Mailing address: Junjiro Kobayashi, MD, Department of Cardiovascular Surgery, National Cerebral and Cardiovascular Center, 5-7-1

Fujishiro-dai, Suita 565-8565, Japan. E-mail: jkobayas@hsp.ncvc.go.jp

ISSN-1346-9843 doi:10.1253/circj.CJ-12-1546

All rights are reserved to the Japanese Circulation Society. For permissions, please e-mail: cj@j-circ.or.jp 


\begin{tabular}{|l|}
\hline $\begin{array}{l}\text { Table 2. Major Concerns in Transcatheter Aortic Valve } \\
\text { Replacement }\end{array}$ \\
Clinical issues \\
Early results \\
Effective orifice area (PPM) \\
Long-term durability \\
Complications \\
Neurologic complication \\
Conduction abnormality (pacemaker implantation, CLBBB) \\
Prosthetic valve regurgitation \\
Myocardial infarction (coronary ostial obstruction) \\
Vascular and bleeding complication, tamponade \\
Renal failure \\
Valve migration \\
Ethical issues \\
Limit of indication \\
Economic issues
\end{tabular}

PPM, prosthesis-patient mismatch; CLBBB, complete left bundle branch block.

is used in patients with atherosclerotic peripheral artery disease and/or aortic aneurysm, which are risk factors for neurologic complications in open-heart surgery. This complication would be partially improved by implantation technique and technology. In the real world, the incidence of stroke is $3-4 \%$, irrespective of device and access site. ${ }^{7,8}$

The cause of complete heart block is mechanical compression of the hard metal frame against the conduction tissue beneath the aortic annulus. The incidence of permanent pacemaker implantation is reported to be $7 \%$ in the European SAPIEN registry (SOURCE), ${ }^{5}$ and $3.4 \%$ and $3.8 \%$ in the respective Partner trials. ${ }^{3,4}$ The implantation of a pacemaker is the most common complication with the CoreValve revalving system, approximately $18.5-42.5 \% .^{7-9}$ As the prosthesis anchored within the annulus, the physiological and anatomical variation in patients and surgical proficiency are thought to be related to the incidence of complete heart block.

Another issue is prosthetic regurgitation. The incidence of moderate to severe regurgitation occurred in $8 \%$ of patients at 2 years in a single-center study. ${ }^{11}$ Prosthetic regurgitation is related to impaired early and late clinical mortality and morbidity. ${ }^{10,11}$ More than moderate regurgitation occurs infrequently and is related to technical errors in valve sizing and positioning. Redilatation or valve-in-valve overlapping may resolve the problem. Balloon expansion of the valve or a degenerative process may cause intravalvular regurgitation. New technologies will resolve peri-prosthetic regurgitation by covering the frame of metal stents in cloth.

The incidence of coronary artery obstruction was $1.2 \%$ and $0.4 \%$ in French ${ }^{8}$ and German ${ }^{9}$ registries, respectively. Myocardial infarction is caused by occlusion of the coronary ostium. Bulky leaflet calcification can occlude the left main coronary ostium. Other risk factors for occlusion are low take-off of the coronary artery, a shallow sinus of Valsalva, and the design of the transcatheter heart valve. Percutaneous coronary intervention or surgical revascularization may be necessary with or without cardiopulmonary bypass. Aortic root angiography during pre-implantation balloon dilatation of the annulus may be helpful to detect any possibility of coronary occlusion.

Vascular and bleeding complications have been already improved by reducing the size of the delivery sheath and catheter. ${ }^{5}$ Post-procedural renal dysfunction is generally mild and reversible. Syngo DynaCT (Siemens AG, Forchheim, Germany) and Heart Navigator (Royal Philips Electronics NV, Koninklijke, The Netherlands) may reduce contrast medium usage during TAVR.

AS in elderly population is a growing problem. The number of patients older than 75 years in Japan is thought to be more than 450,000 by 2020 . TAVR for AS in selected high-risk patients will be realistic in the near future in Japan. Ethical problems regarding the indication of patients and economic issues should be discussed by society.

\section{References}

1. Cribier A, Eltchaninoff H, Bash A, Borenstein N, Tron C, Bauer F, et al. Percutaneous transcatheter implantation of an aortic valve prosthesis for calcific aortic stenosis: First human case description. Circulation 2002; 106: 3006-3008.

2. Guidelines on the management of valvular heart disease (version 2012). Eur Heart J 2012; 33: 2451 - 2496.

3. Leon MB, Smith CR, Mach MJ, Miller DC, Moses JW, Svensson LG, et al. Transcatheter aortic-valve implantation for aortic stenosis in patients who cannot undergo surgery. N Engl J Med 2010; 363: $1597-1607$.

4. Smith CR, Leon MB, Mack MJ, Miller DC, Moses JW, Svensson LG, et al. Transcatheter versus surgical aortic-valve replacement in high-risk patients. N Engl J Med 2011; 364: 2187-2198.

5. Spaccarotella C, Mongiardo A, Indolfi C. Pathophysiology of aortic stenosis and approach to treatment with percutaneous valve implantation. Circ J 2011; 75: 11-19.

6. Maeda K, Kuratani T, Mizote I, Shimamura K, Takeda Y, Torikai K, et al. Early experiences of transcatheter aortic valve replacement in Japan. Circ J 2013; 77: 359-362.

7. Buellesfeld L, Windecker S. Transcatheter aortic valve implantation: The evidence is catching up with reality. Eur Heart J 2011; 32: $133-137$.

8. Eltchaninoff H, Prat A, Gilard M, Leguerrier A, Blanchard D, Fourniat G, et al. Transcatheter aortic valve implantation: Early results of the France (FRench Aortic National CoreValve and Edwards) registry. Eur Heart J 2011; 32: 191 - 197.

9. Zahn R, Gerckens U, Grube E, Linke A, Sievert H, Eggebrecht H, et al. Transcatheter aortic valve implantation: First results from a multicenter real-world registry. Eur Heart J 2011; 32: 198-204.

10. Conradi L, Seiffert M, Treede H, Silaschi M, Baldus S, Schirmer J, et al. Transcatheter aortic valve implantation versus surgical aortic valve replacement: A propensity score analysis in patients at high surgical risk. J Thorac Cardiovasc Surg 2012; 143: 64-71.

11. Bleiziffer S, Mazzitelli D, Opitz A, Hettich I, Ruge H, Piazza N, et al. Beyond the short-term: Clinical outcome and valve performance 2 years after transcatheter aortic valve implantation in 227 patients. $J$ Thorac Cardiovasc Surg 2012; 143: 310-317.

12. Tamburino C, Capodanno D, Ramondo A, Petronio AS, Ettori F, Santoro G, et al. Incidence and predictors of early and late mortality after transcatheter aortic valve implanatataion in 663 patients with severe aortic stenosis. Circulation 2011; 123: 299-308.

13. Ewe SH, Muratori M, Delgado V, Pepi M, Tamborini G, Fusini L, et al. Hemodynamic and clinical impact of prosthetic-patient mismatch after transcatheter aortic valve implantation. J Am Coll Cardiol 2011; 58: $1910-1918$. 